\title{
Üretim Endüstrisi Dijital Dönüşüm Süreci Kavramsal İlişki Haritası
}

\section{The Conseptual Relations Map of Manufacturing Industry Digital Transformation Process}

\author{
Lütfi Apilioğulları ${ }^{\mathrm{a}^{*}}$ \\ ${ }^{a}$ Dr. Öğr. Üyesi, Fenerbahçe Üniversitesi, Mühendislik ve Mimarlık Fakültesi, Endüstri ve Sistem Mühendisliği Bölümü, 34000, İstanbul/Türkiye. \\ ORCID: 0000-0003-3389-9094
}

\section{MAKALE BILGİSİ \\ Makale Geçmişi: \\ Başvuru tarihi: 17 Eylül 2018 \\ Düzeltme tarihi: 08 Kasım 2018 \\ Kabul tarihi: 05 Aralık 2018}

\section{Anahtar Kelimeler:}

Endüstri 4.0

Dijital Dönüşüm

Akıllı Fabrika
ÖZ

Üretim endüstrisindeki KOBI'lerde Endüstri 4.0 / dijitallaşme üzerine çalışmalar yapılmaktadır. Ancak, işletmelerin birçoğu yanlıș stratejiler ve uygulamaların sonucu olarak, dijitalleșme konusunda istedikleri ivmeyi yakalayamamakta ve rekabetçi olamamaktadırlar. Bu sonuç, Endüstri 4.0'a geçiş yöntemlerinin bilinmemesi/uygulanamaması, hangi teknolojinin ne zaman/ nasıl kullanılması gerektiğinin anlaşılamaması ya da stratejik bakış açısı eksiklikleri gibi etkenlerden kaynaklanabilmektedir. Kısıtlı imkana sahip olan Kobilerin, gelişim gösterip, dijital çağa ayak uydurabilmeleri için etkin bir dijital dönüşüm yol haritasına ihtiyaçları bulunmaktadır. Bu çalışmada, Kobilerin dijital dönüşüm sürecinde başarılı olabilmeleri için, uygulamaları gereken kavramların birbirleri ile ilişkisi incelenmiş ve genel hatları ile bir yol haritası modeli çıkarılmaya çalışılmıştır.

\section{A B S T R A C T}

Industry 4.0 / digitalization studies are carried out in SMEs in the manufacturing industry. However, as a result of wrong strategies and practices, they cannot catch the momentum they want for digitalization and cannot be competitive. This result may be due to factors such as lack of knowledge or wrong application of the methods of transition to Industry 4.0, the inadequacy of which technology should be used or the lack of strategic perspective. The SMEs, which have limited opportunities, need an effective digital transformation roadmap to develop and keep up with the digital age. In this study, in order to be successful in the process of digital transformation of SMEs, the relationship between the concepts they need to be studied has been expalained.

\section{Giriş}

Üretim endüstrisinde; Endüstri 4.0, Akıllı Fabrika (Smart Factory), Nesnelerin İnterneti (IoT), bulut (Cloud) ve büyük veri (Big Data) gibi kavramlar oldukça sık uygulama alanı bulmaya başlamıştır. Nesnelerin internetiyle (IoT: Internet of Things); süreçler içinde düşünen, karar veren ve bilgi paylaşan nesneler üzerinden sahadan veriler toplanabilmekte; bilgiye kolay ulaşım ve çalışma esnekliğinin sağlanabilmesi için toplanan bu veriler sanal depolarda / bulutta saklanmakta (Cloud); bulutta saklanan büyük veriler analiz edilip anlamlı hale dönüştürülebilmekte ve bu sayede operasyonel verimlilik artırılabilmektedir (Big Data) (Malavasi ve Schenetti, 2017). Prototip ve kişiselleştirilmiş ürünler 3D yazıcı teknolojisiyle geliştirilip, pazarda hiz avantajı elde edilebilmekte (Additive Manufacturing) (Rohen, 2015); üretim süreçlerinde algılayan, öğrenebilen, karar verebilen robotların kullanılmaya başlanması ile zor ve kalite açısından hassas süreçler daha basit hale getirilip, kalite anlamında 
maksimum hassasiyet yakalanabilmektedir (Autonomous Robots) (Malavasi ve Schenetti, 2017). İşletme içinde dikey, tedarik zincirinde yatay entegrasyon ile süreç ağları (network) genişletilip; süreç entegrasyonuyla bilgi doğruluğu, güvenirliği elde edilerek daha çevik süreçler elde edilebilmektedir (Vertical \& Horizontal Integration). Sadece ürün değil, aynı zamanda üretim süreçlerinin analizleri simülasyon teknikleriyle yapılıp daha verimli süreçler en başta elde edilerek kayıpların oluşmasına izin vermeyecek süreçler tasarlanabilmektedir (Simulation) (Rohen, 2015). Ürün veya hizmetle ilgili tanıtımlar artırılmış gerçeklik teknikleriyle istenilen yere, daha efektif ve hizlı olarak gönderilip maliyet avantajı elde edilebilmektedir

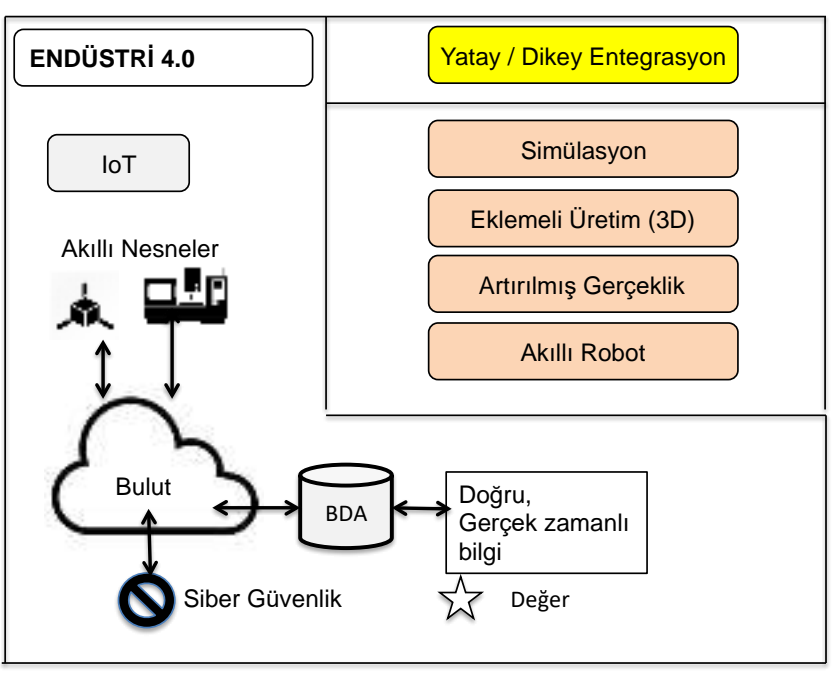

Şekil 1: Endüstri 4.0 ve Bileşenleri

(Augmented Reality) (Vermesan vd., 2015) .

Literatüre ve endüstrideki gelişmelere bakıldığında; Dünya sınıfı üreticilerin geleceğin ürünlerini; şimdiye göre daha hızlı, daha hassas toleranslarda, mükemmele yakın kalitede, daha verimli ve güvenli bir şekilde üretebilmek için ciddi efor harcadıkları görülmektedir (Darmois vd.,2015).

$\mathrm{Bu}$ çalışmada; dijital dönüşümün sağlıklı olarak gerçekleşebilmesi için gerekli olan bileşenler, uzman görüşleri alınarak altı grup altında toplanmış ve birbirleri ile olan etkileşimleri dematel yöntemi ile irdelenmiştir. 1.Stratejik planlama, 2.Kavramsal Tasarım, 3.Endüstri 3.0 koşullarının sağlanması, 4.Nesnelerin İnterneti (IoT Standartları), 5.Veri Entegrasyonu ve 6. İleri Seviye Ürerim standartları olarak gruplandırılmıştır (Apilioğulları, 2018).

\subsection{Problemin Tanımı}

Dünya sınıfi üreticiler (World Class Manufacturer) önce atölye düzeninden (2.0), fabrika (3.0) seviyesine geçtiler. Şimdilerde ise rekabetin başka bir boyut alacağı yeni döneme ayak uydurmak için endüstri çağından, insan makine ve diğer kaynaklarının birbirleriyle, kompleks ağlar üzerinden etkileşimli/işbirlikçi bir modelde çalışabildiği dijital çağ seviyesine (akıllı fabrika, endüstri 4.0) geçmeye çalışıyorlar (Apilioğulları, 2018).
Üretim endüstrisindeki KOBİ'lerde de benzer çalışmalar yapılmaktadır. Ancak, yanlış stratejiler ve uygulamaların sonucu olarak, dijitalleşme konusunda istedikleri ivmeyi yakalayamamakta ve rekabetçi olamamaktadırlar (Apilioğulları, 2018). Bu sonuç Endüstri 4.0'a geçiş yöntemlerinin bilinmemesi/uygulanamaması, hangi teknolojinin ne zaman/ nasıl kullanılması gerektiğinin anlaşılamaması ya da stratejik bakış açısı eksiklikleri gibi etkenlerden kaynaklanabilir (Apilioğulları, 2010). Kısıtlı imkana sahip olan Kobilerin, gelişim gösterip, dijital çağa ayak uydurabilmeleri için etkin bir dijital dönüşüm yol haritasına ihtiyaçları bulunmaktadır.

Bu çalışmada, Kobilerin dijital dönüşüm sürecinde başarılı olabilmeleri için, uygulamaları gereken kavramların birbirleri ile ilişkisi incelenmiş ve genel hatları ile bir yol haritası modeli çıkarılmaya çalışılmıştır.

\section{Dijital Dönüşüm Süreci Önerilen Model}

Dijital dönüşüm süreci içi altı katmandan oluşan bir yol haritası modeli önerilmiştir.

Modele bakıldığında, Kobilerin Dijital Dönüşüm sürecinde öncelikli olarak etkin bir stratejiye ve bu stratejiyi destekleyen eğitim / planlama safhalarına ihtiyaç duyduğu görülmektedir. Bu adım akabinde 3.0 standartlarının ERP / MES gibi araçlar üzerinden sağlanması gereklidir. Endüstri 4.0 teknolojilerinin temeli olan Nesnelerin İnterneti (IoT) konsepti genel olarak 3.0 standartlarının tesis edilmesinden sonra düşünülmelidir. Endüstri 3.0 koşulları tesis edilmeden kurgulanacak teknolojik yatırımlar, yanlışın daha hızlı yapilabilmesine sebep olabilmektedir. Veri entegrasyonu, genel olarak IoT'nin gelişimine paralel olarak gelişse de 3.0 standartlarında da bulut bilişim uygulamalarından faydalanmaktayız. Benzer şekilde ileri seviye üretim standartları da aslında 3.0'dan sonra ya da IoT uygulamalarına paralel olarak düşünülmesi gereklidir.
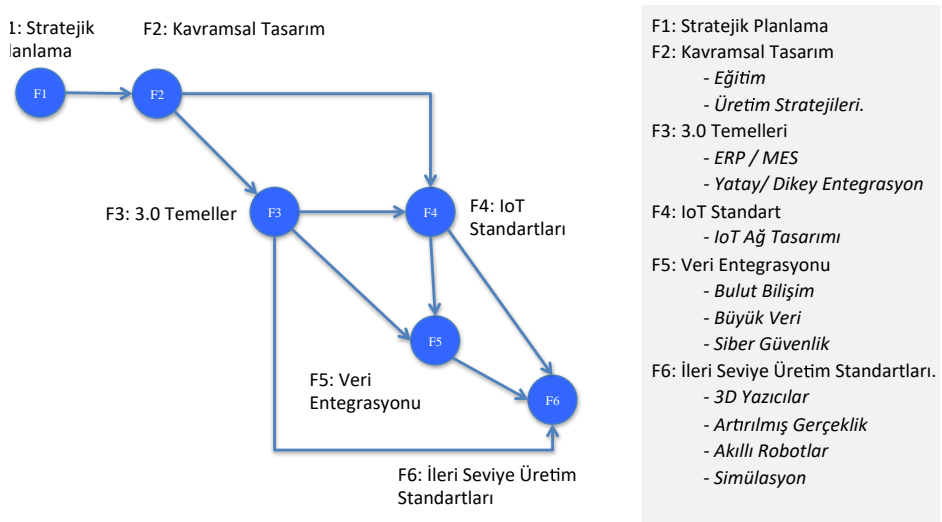

Şekil 2: Dijital Dönüşüm Yol Haritası (Önerilen Model)

\section{Uygulanan Metod}

Bu çalışma üç temel kısımdan oluşmaktadır.

1. Literatür araştırması ve uzman görüşleri üzerinden dijital dönüşüm için gerekli olan kavramlar ve izlenmesi gereken yol haritası tartışılmıştır. Çalışma sürecinde ERP (Enterprise Resource 
Planning), MES (Manufacturing Executing Systems), Dijital Dönüşüm, Yalın / Çevik üretim yönetimi ve prensipleri konusunda uzman kişilerin görüşlerine başvurulmuştur.

2. Otomotiv, kimya, metal, maden, seramik, IT sektörlerinde ortalama on yıl ve üzerinde çalışma yapmış yönetici ve uygulayıcılar uzman olarak kabul edilerek, dijital dönüşüm için izlenmesi gereken yol haritası model önerisinin / hipotezinin çıkarılmıştır. Önerilen model, uzmanlar ile tartışılmış ve konsensüs sağlanmıştır.

3. Çıkarılan modelin, DEMATEL metodu ile geçerliliği test edilmiştir. DEMATEL metodu için benzer sektörlerde, ortalama on y1l ve üzerimde çalışmış başka uzman görüşlerine başvurulmuş ve önerilen modelin geçerliliği test edilmiştir.

\subsection{Dematel}

DEMATEL metodu (The Decision Making Trial and Evaluation Laboratory), karmaşık ve birbirine girmiş problem gruplarının çözümünde kullanılması amacı ile Cenevre Battelle Enstitüsü, Bilim ve insan ilişkileri programı tarafından geliştirilmiştir. DEMATEL metodu bu çalışmada kriterler arasındaki ilişki seviyesinin ve ağırlıklarının belirlenmesi amacıyla kullanılmıştır.

\section{Adım_1: Direkt ilişki matrisinin elde edilmesi.}

Kriterler arasındaki direkt ilişkiler uzman kişiler tarafından, tanımlanmış bir skalaya göre belirlenir. Uzman görüşlerinden elde edilen değerlendirmelerin ortalaması alınarak, direkt ilişki matrisi, $Z$ elde edilir. Çalışmada 0-4 arası bir skala kullanılmıştır. 0: Hiç Etki yok, 4: Çok fazla etki var.

$$
X^{k}=\left[X_{i j}^{k}\right], \quad Z_{i j}=\frac{1}{m} \sum_{i=1}^{m} X_{i j}^{k}
$$

\section{Adım_2: Normalleştirilmiş ilişki matrisinin elde edilmesi.}

Direkt ilișki matrisi Z' ye bağlı olarak normalleștirilmiş ilişki matrisi D aşağıdaki formüle göre elde edilir.

$$
\begin{aligned}
& D=\lambda * \mathrm{Z} \\
& \lambda=\operatorname{Min}\left[\frac{1}{\max 1 \sum_{j=1}^{n}\left|Z_{i j}\right|}, \frac{1}{\max 1 \sum_{i=1}^{n}\left|Z_{i j}\right|}\right] \\
& i, j \in \mathrm{Z}\{1,2, \ldots . n\}
\end{aligned}
$$

Adım_3: Toplam ilişki matrisinin elde edilmesi.

Normalleştirilmiş ilişki matrisi elde edildikten sonra, toplam ilişki matrisi $\mathrm{T}$ aşağıdaki formüle göre elde edilir.

$$
\begin{aligned}
& T=\lim _{m \rightarrow \infty}\left(D+D^{2}+\cdots+D^{m}\right) \\
& T=\sum_{m}^{\infty} D^{m} \\
& T=D(I-D)^{-1}
\end{aligned}
$$

Adım_4: Alıcı ve gönderici hesaplamaları.
Toplam ilişki matrisinin sütunları toplamı (R), satırları toplamı $(\mathrm{C})$ olmakla beraber gönderici $(\mathrm{R}-\mathrm{C})$ ve alıcı $(\mathrm{R}+\mathrm{C})$ hesaplamaları aşağıdaki formüllere göre yapılır.

$$
R=\left(\sum_{j=1}^{n} t_{i j}\right)_{n x 1}, C=\left(\sum_{j=1}^{n} t_{i j}\right)_{1 x n}
$$

\section{Adım_5: Kriterlerin ăğılıklarının hesaplanması.}

$R$ ve $C$ parametrelerinden her bir kriter için ağırlık aşağıdaki formüle göre faktörü hesaplanır. $\mathrm{Bu}$ işlemin ardından her faktörün brüt ağırlığı hesaplanır.

$$
\begin{aligned}
& w_{i}=\sqrt{\left.\left.\left[\left(R_{i}+C_{i}\right)^{2}+\left(R_{i}-C_{i}\right)\right)^{2}\right)\right]} \\
& G w_{i}=\frac{w_{i}}{\sum_{i}^{n} w_{i}}
\end{aligned}
$$

\section{Literatür Taraması Ve Uzman Görüşleri}

Endüstri 4.0 kapsamındaki bileşenler, etkin biçimde dönüşümün sağlanabilmesi için izlenmesi gereken yöntemler / bileşemler altı grupta toplanmış ve kavramsal ilişki biliminde

\subsection{Stratejik Planlama}

Yönetim biliminde strateji, "bir organizasyonun amacina ulaşmak için izleyeceği yollar”, olarak tanımlanır. Stratejik planlama ise bir organizasyon 4. $_{1}$ ne olduğunu, ne yaptığını ve neden yaptığını şekillendiren ve ona bu konularda kılavuzluk yapan temel kararları, eylemleri geleceğe odaklı olarak üreten bir yönetim aracıdır (Apilioğulları, 2013). Bir başka ifade ile bir işletmenin hedeflerine ulaşabilmesi için gereken eylemlerin planlandı $\breve{g}_{1}$, beklenen / istenen yere nasıl ulaşılacağının net olarak tanımlandığı ve belirlendiği süreçtir.

\subsection{Kavramsal Tasarım}

İşletmelerde yeni dönemde, dijital dönüşümden sorumlu başkanlık bölümleri kurulmaktadır. Bu bölümlerin görevi; firma vizyon ve misyonu doğrultusunda, işletmenin gelecekte daha rekabetçi olabilmesi için gerekli stratejik dönüşüm planlamasını yapmak ve uygulamaktır. Bu süreci gerçekleşirken ihtiyaç öncelik analizleri yapmakta ve işletme kaynak yetkinliği ve bütçesi doğrultusunda planlar hazırlamaktadırlar. Uygulanabitlin) ve gerçekleştirilebilir bir plan, dijital dönüşüm için gerekli öncelikli unsurdur (Khan vd., 2016).

4.2.1 Eğitim: Dijital çağın(4petrolü bilgidir ve 4.0'ın temelinde bilgi yönetimi vardır (Apilioğulları, 2018). Teknolojik tabanlı süreç, sistem ve akıllı ürün tasarımı, yeni dönemin uzmanlık gerektiren konularının başında 
gelmektedir. İletişim protokolleri, sensörler ve 4.0 teknolojileri, uygulamalı matematik, istatistik, olasılık gibi konulara hakim olmadan, süreç ve ürün tasarımı yeni dönemde pek mümkün olamayacaktır (Black \& White Paper, Century Link, 2017). Bunun için hangi teknolojinin, nasıl ve nerede kullanılacağını iyi bilen, eğitimli kadrolarınızın olması gereklidir. $\mathrm{Bu}$, işin sistem/teknoloji boyutu olarak tanımlanmaktadır.

Üretimde ideal sistem, mükemmel akış demektir ve akışın tesis edilebilmesi için aynı zamanda doğru yöntemlerin/prensiplerin de iyi bilinmesi gerekir. Teknoloji ne olursa olsun, Yalın üretim felsefesi (verim), Çevik üretim prensipleri (hız) hakkında bilgi sahibi olunmadan, ideal bir üretim sisteminin kurulması oldukça zordur. Dünya sınıfı üreticiler, süreçlerini bu iki felsefe/prensip doğrultusunda yöneterek, rekabet üstünlüğü elde etmektedirler (Malavasi, 2018).

Süreçlerde her daim problem vardır. Sorunlara hızlı atak edip, kalıcı çözüm üretebilmek için sistematik metotlar ve analitik yaklaşımlara ile problemlere bakabilen kadrolara ihtiyaç vardır. DMAIC ve PPS (Practical Problem Solving) metodolojileri endüstride oldukça yaygın kullanılan problem çözme araçlarıdır. Bu metodolojiler (kalite) hakkında bilgi sahibi olunması gereklidir. Süreçleri iyileştirerek, daha çoğu daha azla elde edebilmek ve bunu gerçekleştirirken de hızlı ve kaliteli olabilmek bu yöntemleri bilen, uygulayan insan kaynaklarıyla mümkün olabilir (Black \& White Paper, Century Link, 2017).

Prensipler, metodolojiler ve teknoloji farklı kavramlardır. Yalın/Çevik üretim prensipleri ile süreçler kurgulanır, yönetilir, akışı sağlanır, kayıplar ve belirsizlik yönetilir. Altı Sigma/DMAIC metodolojileri ile değişkenlik minimize edilir, problemler çözülür. $\mathrm{Bu}$ konseptler işin temeli, teknoloji ise bize bunları daha hızlı / doğru yapabilmemize olanak sağlayan bir araçtır (Aitken vd., 2003). 4.0'ın en önemli artısı, karar vermeniz için gerekli olan bilgileri; size gerçek zamanlı ve daha doğru olarak sağlamasıdır (Khan vd., 2016).

4.2.2 Üretim Stratejileri ve Süreç Standartlart: Dijital çă̆, iş stratejilerine bütünsel bakmayı gerektiriyor. Firmaların değil, tedarik zincirlerinin rekabet ettiği bu çağda (SimchiLevi ve Kaminski, 2009) tedarikçiden müşteriye kadar olan tüm süreç birbiriyle iletişimde olmalıdır (Apilioğulları, 2014). Müşterinin davranışından hangi ürün geliştirileceğini anlaşılıp, tedarikçilere zamanında malzeme siparişi verilip, yeni ürünün rakiplerden önce piyasaya sunulabilmesi için tüm sürecin iletişimde olması, bunun içinde doğru iş modellerinin öğrenilmesi, kurgulanması gereklidir. Bilginin dönüşüm hızının haftalar mertebesine indiği günümüz koşullarında, yeni sistem ve teknolojiler öğrenilmez, öğretilmez ve uygulanmazsa, rekabet edilebilmesi oldukça güçtür (Stratton ve Warburton, 2003).

Yapılan işin daha hızlı, kaliteli, güvenli ve verimli yapılabilmesi için teknolojiye ihtiyaç vardır (Yusuf ve Gunasekaran, 1999). Tüm ürünlerin aynı stratejiyle üretilebilmesi mümkün değildir. Bazı ürünler itme, bazıları çekme, bazılarıysa hibrid model (Leagile: Moduler product) üretim stratejileri gerektirir (Christopher, 2000). Malzeme bilgi - süreç ve para akışının en etkin şekilde akabilmesi için, yalın ve çevik prensipler doğrultusunda süreçlerin kurgulanması gerekir. Yanlışı daha hızlı yapmamak, doğruyu hızlı ve etkin yapmak için öncelikle prensipler ve metotlar iyi belirlenmelidir.

$\mathrm{Bu}$ bağlamda tüm iş süreçlerinin kavramsal olarak tasarlanması, süreç paydaşlarıyla mutabakata varılması, yazılı hale getirilmesi ve sürecin yazıldığı gibi kurgulanan yapı üzerinden işlediğinin garanti altına alınması oldukça önemlidir (Apilioğulları, 2018).

\subsection{Endüstri_3.0 Koşullarının Sağlanması}

Endüstri 4.0 konularının en önemlilerinin başında gelen, yatay ve dikey entegrasyonun sağlanabilmesi için sürecin tamamen ERP (Enterprice Resource Planning: Kurumsal Kaynak Planlama) üzerinde yönetilmesi gereklidir (Apilioğulları, 2018). ERP, işletme süreçlerinin standartlar dahilinde, konsolide olarak yönetilmesine olanak sağlayan sistemler bütünüdür. İyi bir ERP olmadan, yeni teknolojilerin sisteme entegre edilebilmesi oldukça zordur. Dünya sınıfı üretici olabilmek için öncelikle; stok yönetiminden üretim planlamaya, maliyet hesaplarından, ürün geliştirme sürecine kadar her şeyin ERP üzerinden yönetilmesi gereklidir.

4.3.1 ERP Entegrasyonu: Ortalama büyüklükteki bir KOBİ'de onlarca iş süreci senaryosu, her senaryonun da 10200 arasında değişen iş adımı mevcuttur. Bu senaryoların çoğu, her gün/değişik adetlerde gerçekleşir. Buna birde binlerce kalem malzeme, yüzlerce tedarikçi-müşteri, kapasite/üretim planlama gibi süreçleri eklenirse, bu işlemlerin düşük seviye yazılımlarla yapılabilmesi oldukça güçleşir. Bu özelliğe sahip olmayan firmalarda yaşanan en temel sorunların başında mevcut iş süreçlerini, etkin yönetememeleri ve bunun sonucunda oluşan kayıplar gelmektedir (Apiliogullari, 2018). Planlama hataları, stok problemleri, doğru ölçülemeyen performans gibi sorunları bu duruma örmek olarak gösterilebilir.

Benzer şekilde doğru maliyet hesabı ve performans analizi içinde gerçek zamanlı, güvenilir bilgiye ihtiyaç vardır. Dijital çağda; toplam kârlılık değil, müşteri ve ürün ailesi bazında kârlılıklar hesaplanmakta ve firmalar düşük kâr ettikleri alanların sebeplerini inceleyerek, alternatif stratejiler geliştirmektedir. Bu durum, artık klasik muhasebe sistemleriyle değil faaliyet tabanlı maliyetlendirme metotlarıyla süreçlerin yönetilmesini gerektirmektedir.

ERP, Endüstri 3.0 konusudur. Yatay entegrasyon ise Endüstri 3.0/4.0 ve Entegre Tedarik Zinciri modelinin ana temalarından biridir. Yukarıda bahsedilen her şeyi tedarikçi ve müşteriyle paylaşmak, sahadan gerçek zamanlı verileri alıp talep odaklı planlama yapabilmek, ürün geliştirme süreçlerinde tedarikçilerle etkin iletişim kurulabilmesi için yatay / sanal entegrasyonun kurulması gereklidir. Bunun için yüksek güvenirlikli, genişlemeye açık bir ERP'ye 
gereksinim bulunmaktadır. Dolayısıyla, Endüstri 4.0 dönüşümü için öncelikle iş süreçleri standartları belirlenmeli ve tüm süreçlerim ERP üzerinden yürümesi tesis edilmelidir (Apilioğulları, 2018).

ERP kurulumu ile iş süreçlerinin tamamen standartlar dahilinde işletilebilir. Bugün birçok ERP projesinin patladığını, istenilen sonuçları üretemediğini görmekteyiz. $\mathrm{Bu}$ sonucun nedenleri olarak zamanlama, kurgu hatası ve yanlış yönlendirmeleri gösterebiliriz. ERP, kavramsal tasarım kurgusu üzerine işleyen bir yazılımdır. Ne derece doğru kavramsal kurgu yapılır ve sisteme de ne denli az müdahale edilirse, o derece doğru çalışır. ERP sürecinin doğru kurulabilmesi için öncelikle süreçlerin tam olarak tanımlanması gereklidir. Standartlar ve kavramsal tasarım süreci doğru yapılmadan, ERP kurulumunun sağlıklı yapılabilmesi pek mümkün değildir. Ancak, ERP kurulumu olukça meşakkatli ve uzmanlık isteyen bir süreçtir. Yetkin ve ideal sayıda kadronuzun olmaması, yanlış ERP seçimi, zaman darlığı gibi konular, ERP kurulumlarında istenilen başarının yakalanamamasına neden olabilmektedir. $\mathrm{Bu}$ bağlamda, ERP süreci öncesi süreci yönetecek yetenekte kadroların olması, ekiplerin ERP üzerine eğitilmesi, doğru ERP seçimi ve nitelikli danışmanının seçilmesi, başarısızlık riskini en aza indirgeyebilmektedir.

Kısaca, kavramsal tasarımı tamamlanmış iş süreçlerinin, genişlemeye uygun bir ERP üzerinden yönetilmesi, dijital dönüşüm öncesi tesis edilmesi gereken bir diğer temel koşuldur. Standart ve ERP mevcut ise Endüstri 3.0 koşulları sağlanmış demektir. Bu gereksinimler sağlanmadan 4.0 uygulamalarına geçiş, yanlışın daha hızlı yapılmasından başka bir sonuç doğurmayacaktır (Apilioğulları, 2018).

4.3.2 MES Entegrasyonu: Eğitim, standart ve ERP adımlarını hazırlık aşaması olarak adlandırılabilir. Bu aşamadan sonra, ERP ile başlayan fabrika içi dikey entegrasyonun MES (Manufacturing Execution System) ile desteklenmesi gereklidir. Üretim kontrol, izleme ve düzetme adımlarının sağlıklı yapılabilmesi için sahadan gerçek zamanlı verilerin alınıp/yorumlanabilmesine gereksinim vardır. MES, bu anlamda ERP sistemiyle entegre bir şekilde çalışarak, bu işlevi yerine getiren ideal bir yapıdır.

MES üzerinden süreçlere gerçek zamanlı iş emri, ürün dokümanı, kontrol planı gönderebilir, üretim süreçlerinden bilgi alabilir (üretim adetleri, fire, OEE, vs.), otomatik üretim performans raporları türetebilir, bu bilgileri görsel olarak yayınlayabilir ve kaynaklar daha etkin yönetilebilir. Akıllı fabrika uygulamasının ilk adımı olan MES'ler sayesinde bugün birçok firma gerçek zamanlı OEE analizleri yapmakta, problemli süreçlerini analiz ederek, zamanında aldıkları aksiyonlarla rakiplerine oranla daha verimli süreçlere sahip olmaktadırlar.

Endüstri 4.0 üretmekten ziyade, verimli üretmek için düşünülmelidir (Malavasi vd.,, 2017). Teknoloji ne olursa olsun, hâlâ metal kesilecek, bükülecek ve montaj yapılacaktır. Üretim ve süreçlerin daha etkin yönetilip, hız, kalite ve maliyet anlamında avantaj elde edilebilmesi için teknolojiye ihtiyaç vardır. Yüzlerce ürün, binlerce malzeme ve onlarca sürecin olduğu, her an her şeyin değiştiği ve kontrol etmenin giderek güçleştiği dinamik üretim ortamında, teknoloji; süreçleri yönetmekten sorumlu, sanal yönetici (Technology: Virtual Manager) olmalıdır. MES bu iş için ideal bir araçtır.

4.3.3 Yatay / Dikey Entegrasyon: ERP ve MES ile birlikte fabrika içi dikey entegrasyon tamamlanabilir. Dikey entegrasyon akıllı fabrika sürecinin yapı taşlarındandır. Üretim süreçlerinin yönetilmesi: iş emri gönderme, sahadan veri toplanma, performans/kalite analizlerinin yorumlanması ve aksiyona geçmek için gerekli olan tüm bilgi, dikey entegrasyon üzerinden sağlanabilir. MES, Endüstri 4.0 teknolojilerinin gelişimine paralel olarak, işletme süreçleri açısından artık olmazsa olmaz bir araç haline gelmiştir. Yalın üretim felsefesinin yapı taşlarından olan Asakai (üretim toplantıları) toplantıları (Apilioğulları, 2010). MES ve 4.0 teknolojileri üzerinden artık dijital olarak yapılmaktadır (Digital Asakai).

Yatay entegrasyon ise süreçlere tedarikçi ve müşterilerinde katılımıyla akıllı zincir (Smart Chain) elde edilebilmesine olanak sağlar. Bu sayede, tedarikçi-üretici ve müşteri, sanal ortamda buluşarak, bilgileri güvenli/doğru şekilde paylaşır, iletişim maksimizasyonu elde eder ve sanki aynı ortamdaymış gibi üretim planlama, ürün geliştirme gibi süreçlerini daha etkin, verimli ve hatasız olarak gerçekleştirebilirler.

\subsection{Nesnelerin İnterneti (Iot)}

IoT dijital çağın üretim standardıdır (Apilioğulları, 2018). Bilginin, en önemli rekabet unsuru olduğu günümüz koşullarında, teknoloji tabanlı süreçlere sahip olmak oldukça önemli bir rekabet unsurudur (Rohen, 2013).

$\mathrm{Bu}$ adıma kadar yapılması gerekenleri Endüstri 4.0 için hazırlık süreci olarak adlandırılabilir. Şu ana kadar olması gerekenlerin kurumsal işletmelerin çoğunda olduğunu görmekteyiz. 4.0 süreci aslında buradan sonra başlamaktadır. Planlama evresi, her dönüşüm sürecinde olduğu gibi burada da yapılması gereken en stratejik iş adımıdır. Bu aşamadan sonra; akıllı fabrika, akıllı zincir süreçlerine geçiş için stratejik planların yapılması gerekir (Khan ve Turowkski, 2016).

4.4.1 IoT Ă̆ Tasarımı (IoT Network Design): Üretimde doğru üretimi yapabilmek için bir çok verinin; hazırlanmasına (0. Preperation: İş Emri), ilgili yerlere iletilmesine (1.Transmittting: Dokuman, Teknik resim), süreçlerde işlenmesine (2.Processing: Set-up \& Parametre \& Run), sahadan toplanmasina (3.Capturing: Üretim bilgileri; adet, fire, süre, duruş vs.,), analiz edilmesine (4.Analyzing: OEE, vs.,), raporlanmasina (5.Reporting:) ve buradan anlamlı sonuçlar çıkararak kararlar alınması (6.Desicion Making) gereksinim vardır. Bu veri trafiği; bir ürün, bir süreç için böyleyken, yüzlerce ürün, yüzlerce prosesin olduğu bir işletmede, üzerine tedarikçiler ve müşterilerin de eklenmesi ile oluşan tedarik zincirinde çok daha kapsamlı bir boyuttadir. 
İşletmelerin yaşadıkları sorunların başında, veri trafiğini / bilgi çevrimini etkin yönetememeleri gelmektedir. $\mathrm{Bu}$ trafiğin, süreçler arasında entegrasyon (yatay/dikey) olmadan ve büyük veri yönetimi stratejileri geliştirilmeden yönetilebilmesi artık olanak dışıdır. Üretim ortamlarının, giderek daha dinamikleştiği dijital çağda, bilgi yönetimi stratejik öneme sahiptir. Yeni dönem, bilgi yönetimi üzerine şekillenmektedir (Dopico vd., 2016).

Akıllı fabrika; insan, makine ve ortam içinde bulunan nesnelerin, yazılım/donanımlar aracılığıyla, birbirleriyle etkileşimli iletişime geçip işbirlikçi bir yapıda çalışabildiği ve birçok akıllı nesnenin özerk olarak kararlar alabildiği sistemler bütünüdür. IoT ile nesnelere kimlik kazandırabilmekte, nesneyi bir varlık haline dönüştürebilmekte ve kimliği (ID) olan bir nesneye her yerden bilgi gönderilip/alınabilmektedir. Üretimin yeni standartları IoT devrimi üzerine kurulmaktadır.

Dijital çağda birçok uygulama IoT ağları üzerinden gerçekleştirilebilecektir. IoT'nin kullanılır olmasının en büyük avantajlarından biri gerçek zamanlı veriye, mobil olarak ulaşabilecek olunmasıdır. Bu sayede gerçek zamanlı analizler yapılıp, daha doğru/hızlı kararlar alabilme şansı yakalanabilmektedir.

- Üretimdeki bir makinenin, üzerindeki sensörler ve yazılım algoritmalarıyla arıza yapmadan önce bakım gereksinimini belirtmesi (Smart Process Control),

- Ürünlerin karakteristiklerine göre kendi üretim rotalarını belirleyebilmesi (Smart Routing),

- Kimyasal proseslerin bir sonraki ürüne göre otomatik olarak proses parametrelerini ayarlayabilmesi ya da dış ortam değişimlerine karşı kendini re-Configure edebilmesi (Smart DeCentralized Desicion)

- Akıllı robotların ortam şartlarına en uygun davranışa analizler sonucunda karar vermesi (Autonomous Robots),

- Ürün ve ürün taşımasında kullanılan palet/konteynerlerin izlenebilmesi (Smart Tracebility),

- RFID uygulamalarıyla depo operasyonlarında ürün arama, sayma gibi gereksiz işlerin ortadan kalkması (Smart WH Management),

- Ürün geliştirme sürecinde bazı parçaların 3D yazıcılarla üretilmesi (Fast Development),

- Simülasyon teknikleriyle sanal ürünler üzerinden lansmanların ve ürün geliştirme sürecinin yönetilmesi, yapay zekâ algoritmalarıyla akıllı ürünler ve nesneler üzerinden alınan verilerden anlamlı, yapılandırılmış bilgi türetilerek (ne üretilecek, ne sipariş açılacak, vs.) kapasite, üretim planlama süreçlerinin etkin yönetilmesi (Agile Manufacturing),

Bu bağlamda; dijital dönüşüm bu adımında IoT networke bağlanacak nesnelerin, ekipmanların belirlenmesi ve planlanması düşünülmesi gereken ilk adımdır.
- Ağa bağlı olacak nesneler nelerdir ? (Süreç/Ekipman, Ürün, vs..)

- $\mathrm{Bu}$ nesnelerin halihazır teknolojileri, mevcudu geleceğe taşımaya uygun mu dur? Değilse; modifikasyon, versiyon yükseltme, yenisi ile değiştirme gibi stratejilerden hangisi uygulanacaktır? Bu işin bütçesi nedir?

- Nesneler ve sistem arasında ne tür veri trafiği olacaktır? Ne gönderilmek, ne alınmak ya da ne kontrol edilmek istenmektedir istiyoruz ? (İş emri/döküman göndermek, üretim/fire rakamlarını almak, proses parametrelerini kontrol etmek, verimlilik hesaplamak, ürün izlemek, vs.)

- Network trafiği nasıl yönetilecektir ? Veriler nerede, nasıl depolanacak, nasıl analiz edilecek / raporlanacaktır? Bunlar için ne tür donanım/yazılım ve kurulumlara gereksinim olacaktır ? $\mathrm{Bu}$ işin bütçesi nedir?

- IoT Network bakımı/güvenliği nasıl sağlanacaktır? IoT ağ nesnelerinin yazılım güncellemeleri/ bakım faaliyetleri nasıl yapilacaktır?

- Ve, en önemlisi bu işin sponsoru/yöneticisi kim/ler olacaktır?

\subsection{Veri Entegrasyonu (Cloud Computing \& Big Data)}

Veri yönetiminde, standartlaştırılmış yaklaşım eksikliği endüstriyel çağ işletmelerin en öncelikli sorunlarından biridir (Vermesan, 2015). Üretim ortamlarının son derece dinamik olması ve teknolojik yetersizlikler bunun temel nedenlerindedir (Apilioğulları, 2018).

Dinamik üretim ortamlarında işlerin planlanması ve koordine edilebilmesi, süreç performansının izlenmesi, problemlerin analiz edilebilmesi için sürekli veri üretilir, gönderilir/alınır. Alınan veriler yorumlanır, yeni kararlar alınır, daha sonra yeniden veri olarak üretilir ve gönderilir. İş emirleri, ürün/süreç dokümanları, kontrol planları, üretim verileri, planlı bakım, vs. Ancak sahadan gelen farklı formattaki verilerin (yapılandırılmamış veri), değişik platformlarda saklanması (veri siloları), Excel /Word gibi programlarla analiz ve güncelleme süreçlerinin yapılmaya çalışılması (veri manipülasyonu), iş formlarının/süreç dokümanlarının manuel ya da e-mail yoluyla iletilir olması sonucunda (veri güvenirliği), süreçler/bölümler arasında hatalı, geç veri paylaşımı yapılabilmekte, bunun sonucunda istenilen çıktı elde edilememekte, performans ve maliyet kayıpları yaşanabilmektedir (Rohen vd., 2015). Eski ürün dokümanı üzerinden hatalı üretim yapılması (kontrollü kopyanın güncellenmemesi ya da eskisinin hâlâ üretimde olması), yanlış malzeme kullanımı (ürün ağacının güncellenmemesi ya da güncellenen ürün ağacının sahaya iletilmemesi), farklı ürün üretimi (iş ermininin yanlış okunması) veya makinenin bakımsızlı nedeniyle beklenmeyen bir anda arıza yapması (makine duruşlarının zamanında analiz edilmemesi) gibi problemlerin nedenlerinde biri veri yönetimi/iletimi ve analizinde yaşanan sikıntılardır (poor data management).

Süreçleri yönetebilmemiz için güncel, ulaşılabilir ve gerçek zamanlı veri akışının/analizin olabilmesi son derece 
önemlidir. Ancak veri yönetiminde kullanılan ara çözüm bollukları; veri siloları, tekrarlamalı/tutarsız veriler oluşmasına; veriye ulaşamama, yorumlayabilme güçlükleri yanlış ya da geç kararlar alınmasına neden olmaktadır (Malavasi vd., 2017). Bu sorunları giderebilmek için veri yönetiminde standartlaştırılmış yaklaşımın sergilenmesi gereklidir.

4.5.1 Bulut Bilişim (Cloud Computing): Yazılım ve network ağları bizi kendi kurallarına çekiyor. İş süreçlerinin yönetiminde IT teknolojilerini etkin kullanmadan sonuç üretilebilmesi neredeyse imkansız bir hale gelmektedir (Khan ve Turowkski, 2016). Ürün geliştirmek için CAD gibi kompleks yazılımlara, üretimi yönetmek için ERP, müşteri ilişkileri için CRM gibi sistemlere, gerek iç gerek dış dünya ile iletişim kurabilmek için de network ekipmanlarına ihtiyaç duyuluyor, ve hiç de azımsamayacak oranda maliyetlere katlanılmaktadır. Lisans maliyetleri, donanım maliyetleri, yönetim maliyetleri.

Bulut Bilişim, gerekli olan bu üç bileşeni, talep edildiği anda, her daim kullanıma hazır ve kullanıldığı kadar ödemek üzere kurgulanmış bir modeldir. Aynen, elektriğe ihtiyaç olduğunda, cihazların prize takılıp - enerji ihtiyac1 giderildiği gibi bulut bilişimde de ihtiyaç olan uygulama, platform ve donanıma sanal olarak ulaşıla bilinmektedir. Elektriğin nasıl üretildiği/dağıtıldığı hakkında bilgi sahibi olunması gerekmediği gibi bulut bilişimde de işin arka planında ne olduğunun bilinmesi gerekmez. İhtiyaç olan depolama alanı, iş süreçlerini yönetmek için gereken donanım/yazılım ve platformlara artık bulut üzerinden ulaşabilinmektedir.

Bu bağlamda, depolama işlevi için bulut teknolojileri üzerine inceleme/planlama yapılması ve gerekli tüm bilgilerin ortak/sanal platformlarda saklanması hem veri silolarının ortadan kalkmasına hem de verilerin mobil olarak istenilen yerden ulaşabilmesine olanak sağlamaktadır. Özellikle ürün dokümanlarının oluşturulması, güncellenmesi ve iletilmesi aşamalarında tek bir depolama kaynağının kullanılması, doküman yönetimi ve güvenirliği açısından oldukça fayda sağlamaktadır (Rohen vd., 2015).. Benzer şekilde işletme yazılım/platform ve network donanım gereksinimlerinin analiz edilip, bulut üzerinden ilgili servislerin alınması için stratejik planların yapılması da bu aşamada düşünülmesi gereken konulardandır.

4.5.2 Büyük Veri (Big Data): İnovasyonun ana itici gücü bilgidir. Bilgiye ulaşan, analiz eden ve bundan faydalı, anlamlı sonuçlar çıkarabilen işletmeler, her açıdan rekabet üstünlüğü elde etmektedirler.

Nesnelerin İnterneti (IoT: Internet of Things) ile süreçlerin birçok yerinden, farklı formatlarda veriler alınabilmektedir. $\mathrm{Bu}$ durum hem veri miktarında hem de hızında artışa sebep olmaktadır. Süreçlerde üretilen, farklı formatta, yapılandırılmamış veriler heterojenik bir veri yapısı oluştururlar (Heterojenik Veri: Birbirine yakın özellik/nitelik göstermeyen veri kümesi). $\mathrm{Bu}$, büyük ve kompleks verinin depolanması, analiz edilmesi ve raporlanması için yeni kuramlara, metotlara gereksinim vardır. Depolama işi bulut üzerinde gerçekleşir, ancak analiz ve raporlama süreci için farklı yaklaşımlara ihtiyaç vardır.

Heterojenik veri yapısından, anlamlı bilgi türetebilmek için yeni algoritmalar, modeller ve görselleştirme teknikleri gereklidir. Büyük veri; yüksek hacimde, belirsiz ve çok çeşitlidir. Buradan anlamlı bilgi türetebilmek için analizlere, algoritmalara ihtiyacımız vardır. Veri madencileri, korelasyonlar üzerinden önce verileri gruplar, sonra algoritmalar üzerinden büyük veri akışını analiz ederek/raporlayarak, veriden faydalı bilgi türeterek, doğru karar alınabilesine destek olurlar. Örneğin; Akıllı ürünler üzerinden müşteri davranışlarını izleyerek, yeni ürün özelliklerinin ne olması gerektiği tespit edilerek, pazara hızlı girme konusunda avantaj elde edilebilir ya da üretim/kapasite planlamaları daha doğru yapılabilir. Üretim verilerinden, süreç performansları gerçek zamanlı analiz edilip zamanında tedbirler/önlemler alınabilir.

Dijital çağın en öncelikli konularının başında; veriden anlamlı bilgi türetmek gelmektedir (Apilioğulları, 2018). Veri yönetiminde standart yaklaşım dijital dönüşümde öncelikli olarak ele alınması gereken konuların başında gelmektedir. Dijital çağda veri analistliği/madenciliği oldukça önemli konuların başında gelmektedir. Bu bağlamda uygulamalı matematik, istatistik/olasılık gibi teorik konuları çok iyi bilen veri analistlerine ihtiyaç olacaktır.

Veri entegrasyonunun işletme içinde sağlaması akabinde, sürecin tedarikçi ve müşterilere doğru uzatılması planlanmalıdır: Teknoloji tabanlı proses entegrasyonu. Zira, rekabetin tedarik zincirinde oluyor olması ve tedarik zincirinin de her aşamada veri üretiyor olması sonucunda, büyük verilerin, süreç entegrasyonuyla tedarik zinciri bazında analiz edilmesi, yorumlanması zincirin daha çevik, verimli olmasına etki edecektir (Apilioğulları, 2018).

4.5.4 Siber Güvenlik (Cyber Security Data): Nesnelerin giderek artan bir oranda internete bağlanması, bulut teknolojileri ve büyük veri kavramları veri güvenliği / yönetimi konusunu başka bir boyuta getirmiştir. İşletmeler artık tüm verilerinin güvenliğini iç/dış tehditlere karşı korumak zorundadırlar (Malavasi vd., 2017).

\section{6. İleri Seviye Üretim Standartları}

İleri seviye üretim standartlarına geçişin bazı adımları bu aşamada düşünülebileceği gibi bazı kavramlar, bir önceki aşamada da kapsam içine alınabilir.

4.6.1 Dijitalden - Gerçeğe (3D Printing): Dijital çağda ürün yaşam süreleri kısalmakta, bunun sonucunda kişiselleştirilmiş ürünlere rağbet artmaktadır. Yeni dönemde rekabet, kişiselleştirilmiş ürünleri, seri üretim performansında yapabilmeye, bu da ancak değişiklikleri iyi yönetmeye endekslidir (Stratton ve Warburton, 2003).

Üretim süreçlerinde değişiklik yönetimi oldukça sıkıntılıdır. Üretim süreçlerini, hatları hızlı bir şekilde yeniden ayarlamak, konfigure edebilmek kolay olmadığı gibi 
maliyetlidir de. Endüstriyel çağ işletmelerindeki iletişim, planlama, koordinasyon eksiklikleri (veri eksikliğine dayalı), teknolojik yetersizlik ve düşük bilgi seviyesi, proseslerin esnek olmasını desteklemez (Aitken vd., 2003). $\mathrm{Bu}$ durum çeviklik karşısındaki en büyük engellerdendir. Ancak, yeni dönemde üreticiler değişiklikleri sıklıkla yapmak zorunda kalacaklardır. Daha sık ürün geliştirilecek, küçük adetlerle daha sık değişim olacaktır (Towel ve Christopher, 2002). Pazara erken girmek için hızlı ürün geliştirmelidir.

3D yazıcılar, sanal ortamdan fiziksel ürün gerçekleştirerek çevik olabilmemize olanak sağlamaktadır (Towel ve Christopher, 2002). Prototipleri ya da siparişi ' 1 ' olan üretimleri hizlıca yapabilmekte (Apiliogullari, 2018), bir yerde sanal olarak yapılan ürün, başka bir yerde fiziksel olarak elde edilebilmektedir. Ancak, bu konuda daha alınması gereken epey mesafe vardır. İşlem hızı ve işlenebilen malzemelerin kısıtlı olması, bu teknolojinin üretim sektöründe henüz istenilen yerde olmasını engellemektedir. Bu bağlamda, bu teknolojiyi araştırmak, takip etmek, öğrenmek ve geleceğe hazır olmak şu aşamada düşünülmesi gereken bir konudur.

4.6.2 Sanallaştırma / Simülasyon (Product - Process Plant): Dijital ortam üreticilere oldukça kolaylıklar sağlamaktadır. Üreticiler kararlarını, fiziksel ürün üretmeden, geliştirme maliyetlerini çok artırmadan alabilmektedir (Darmois vd., 2002). Simülasyon ve artırılmış gerçeklik uygulamaları ürün geliştirme, servis hizmetleri, pazarlama gibi alanlarda teknoloji temelli firmalarda oldukça sık kullanılmaktadır.

Simülasyon teknikleri 3.0 döneminde de vardı. CAD (Computer Aid Design) yazılımları üzerinden, ürün geliştirme ve testleri sanal ortamda yapılabilmekteydi. Bu süreç, ürünleri fiziksel olarak üretmeden, sanal ortamda test edilmesine olanak sağladığı için hı/maliyet anlamında işletmelere yarar sağlamaktadır. $\mathrm{Bu}$ aşamada ilk düşünülmesi gereken konu mevcut teknolojinin ne denli iyi kullandığıdır. Bu tür tasarım ve simülasyon programlarının lisans maliyetlerinin yüksek olması, eğitim konusunda isteksiz davranılması sonucunda, işletmeler istenilen performansi tam olarak elde edememektedirler. $\mathrm{Bu}$ bağlamda öncelikli olarak bu konudaki yetkinliğin artırılması yönünde politikalar geliştirilmelidir.

CAD ortamlarına oluşturulan ürün dokümanlarının saklanması/yönetimi (ECM: Engineering Change Management) bir diğer önemli konudur. Teknik resimlerin, ürün ağaçlarının revizyon/versiyon takiplerinin etkin takibinin yapılarak, sürekli güncel bilginin hazır ve ulaşılabilir olması için ürün data yönetimi (PDM: Product Data Management) konusunda yatırım yapılması da, yine bu aşamada düşünülmesi gereken bir konudur.

Simülasyon teknikleri artık süreç ve fabrika seviyelerinde de kullanılabilmektedir. Yeni kurulacak bir sürecin davranışını gözlemlemek ya da ideal süreç akışını, insan/makine ve ürün kapsamında test edebilmek için gelişmiş yazılımlar her geçen gün artış göstermektedir.

4.6.3 Artırılmış gerçeklik (Augmented Reality): Endüstri 4.0'ın çığır açan teknolojilerden biri artırılırmış gerçeklik uygulamalarıdır. Yeni ürün lansmanlarının yapılmasında, servis yönetiminde ya da depo/lojistik uygulamalarında örneklerine rastlanmaktadır. Çok yakın bir gelecekte, üretim yönetimin en önemli araçlarından biri olacak bu konu üzerine araştırma yapmak ve zamanı geldiğinde hazır olmak gereklidir.

4.6.4 Robot (Autonomous Robots): Robotların bir çok versiyonu üretim endüstrisinde epeydir kullanılmaktadır. Proseslerde kullanılan kaynak/boya/montaj robotları, akıllı depolama sistemlerinde çalışan robot Craneler (ASRS: Automatic Storage Retrieval System), sahada manyetik şerit üzerinde, katarları çeken robot arabalar (AGV: Automatic Guided Vehicle) gibi bir çok yerde robotları görmekteyiz. Robotlar tekrarlamalı işlerde, standardın, kalitenin ve iş güvenliğinin üst düzeye çıkmasına yardımcı olarak, hız/maliyet anlamında avantajlar getirmektedirler.

4.0 teknolojilerinde yukarıda bahsedilen robotların daha ötesinde bir konsept ile karşı karşıyayız. Akıllı, yani öğrenebilen ve iş ortamında insan ile birlikte çalışabilen robotlar. Hizmet sektöründe bazı örneklerini görmekle birlikte, üretim süreçlerinde akıllı robotların etkin bir şekilde yer almasına biraz daha zaman olsa da, geleceğe hazırlanmak için, mevcut robotların IoT ortamına taşınarak uzaktan yönetebilir olması, olası süreçlerde robot yatırımlarına gidilerek, hem bu teknoloji ile tanışılmasına hem de süreçlerde standartların artmasına katkı sağlayacaktır.

\section{Dematel İle Model Güvenirliğin Test Edilmesi}

$\mathrm{Bu}$ aşamada; önerilen model DEMATEL yöntemi ile güvenirlik testine tabi tutulmuştur. Farklı sektörlerde çalışan, toplam on bir uzmandan, altı faktörün aralarındaki direkt etkileri, tablo_1'e göre belirlemeleri istemiş, verilen

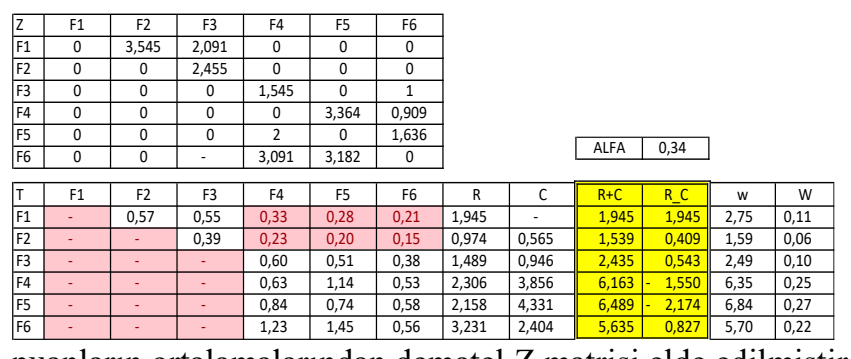

puanların ortalamalarından dematel $\mathrm{Z}$ matrisi elde edilmiştir (Eq_4.1). DEMATEL $Z$ tablosu, dematel metodunda belirtilen adımlar uygulanarak ' $\mathrm{T}$ ' matrisi (Eq_4.7), alfa katsayıs1 ) ve alıc1/gönderici puanları (Eq_4.8), faktör ağırlıkları / önem dereceleri (Eq_4.9, Eq_4.10) hesaplamaları yapılmıştır.

Tablo 1: DEMATEL Z ve T Matris 


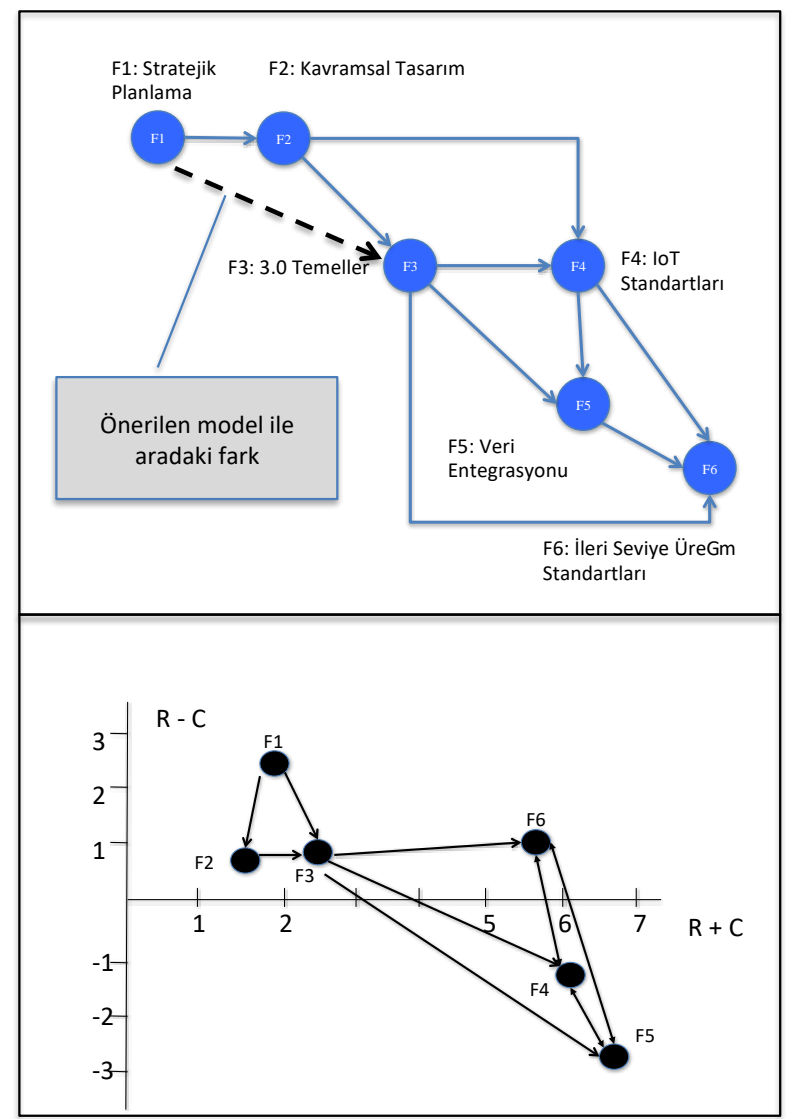

Şekil 3: DEMATEL Sonuç: A ğ ve Sebep / Etki Diyagramı

Tablo_1'den görüldüğü üzere;

- F1 (Strateji) faktörü ana etkileyici, F2 (Kavramsal Tasarım) ikinci etkileyici unsurdur.

- F2 (Kavramsal Tasarım) faktörü sadece F1(Strateji) den etkilenmektedir.

- F3 (3.0 Temelleri) faktörü, hem F1(Strateji) den, hem de F2 (Kavramsal Tasarım) faktöründen etkilenmektedir.

- Önerilen model ile DEMATEL arasında gerçekleşen tek fark buradadır. Bu sonuç modelin geçerliliği yönünde önemli bir kanıttır.

- F4 (IoT) faktörü, F3 (3.0 Temelleri) faktöründen etkilendiği gibi, F2 (Kavramsal Tasarım) faktöründen, F5 (Veri Entegrasyonu) faktöründen ve F6 (İleri Seviye Üretim Teknolojileri) faktöründen de etkilenmektedir.

- F5 (Veri Entegrasyonu) faktörü, F3 (3.0 Temelleri) faktöründen etkilendiği gibi, F6 (İleri Seviye Üretim Teknolojileri)) faktöründen, F4 (IoT) faktöründen ve F3 (3.0 Temelleri) faktöründen de etkilenmektedir.

- F6 (İleri Seviye Üretim Teknolojileri) faktörü, F3 (3.0 Temelleri) faktöründen, F4 (IoT) faktöründen ve F5 (Veri Entegrasyonu) faktöründen etkilenmektedir. $(\mathrm{R}+\mathrm{C})$ ve $(\mathrm{R}-\mathrm{C})$ değerlerine baktığımız zaman - $(\mathrm{R}-\mathrm{C})$ değerlerinin etkilenen, $+(\mathrm{R}+\mathrm{C})$ değerlerinin ise etkileyen faktörler olduğunu görmekteyiz. F4 (IoT) faktörü ve F5 (Veri Entegrasyonu) faktörler, negatif (R-C) değerine sahip olduğundan etkilenen, diğer faktörler ise etkileyen olarak nitelenebilirler. Faktör ağırlıklarına baktığımız zaman F5 > F4 > F6 > F1 > F3 $>$ F1 olduğunu görmekteyiz. Bu durumu Endüstri 4.0'1n IoT ve Veri Entegrasyonu üzerine konuşlandığının göstergesi olarak algılanabilir.

\section{Sonuç ve Tartışmalar}

Dijitalleşme konusunda sistematik bir yaklaşım ve bir metodolojinin izlenmesi, dönüşümün daha sağlıklı olabilmesi açısından yarar sağlamaktadır. Stratejik yaklaşım bu aşamada önem arz etmektedir. Ancak, işletmelerin; kendi mevcut durumlarını irdelemeden, yorumlamadan ve standart iş süreçlerini kurgulamadan dijital dönüşüm sürecine başlangıç yapmaları sonucunda istenilen getiri elde edilememektedir. Teknoloji, standartlar üzerine kurgulanması gereken bir araçtır. Standart, binanın temeli; teknoloji ise binayı yükselten kolonlardır. O nedenle, iş standartları belirlenmeden, yapılmaya çalışılan teknolojik değişimler, işletmelerin yanlışı daha hızlı yapmalarına sebep olmaktadir.

Standart belirlemek ve teknolojik değişimin özünde bilgili olmak yatar. Yeni dönemin ve inovasyonun itici gücü bilgidir. Bilgili olmak, standartların belirlenebilmesine, üzerine teknoloji giydirilebilmesine destek olarak akıllı bir sistem elde edilmesine - Akıllı sistem de sürekli bilgi üreterek işletmelerin daha hızlı ve doğru karar alabilmesine olanak sağlar. Dijital çağda rekabet, bilginin gücünden geçiyor.

\section{Kaynakça}

Aitken, J, Childerhouse, P, (2003), The impact of product life cycle on supply chain strategy, International Journal of Production Economics, Vol. 85, 127-140.

Aitken, J, Childerhouse, P, Towill, D, (2003), The impact of product life cycle on supply chain strategy, International Journal of Production Economics, Vol. $85,127-140$.

Apiliogullari, L., (2018). "The Road Map of Digital Transformation", Aura Publishing, ISBN: 978-605103-381-5, İstanbul

Apiliogullari, L., 2014, “Lean supply chain and it's effect on company key performance indicators and an industry applications", XII. Logistic and Supply Chain Congress.

Apiliogullari, L., 2015, "The Effect of Postponement Strategies on Company KPIs", ICOVACS-201, 6th International Conference on Value Chain Sustainability,

Apiliogullari, L., 2014,’Tedarik zinciri süreçlerinde toplam maliyet ve nakit akış hızı kavramlarının finansal sonuçlar üzerine etkisi”, Loder, Vol. 76, 20-26.

Apiliogullari, L., (2010). "Lean transformation: The code of productivity”, System Publishing, ISBN: 978-975-322576-2, İstanbul

Apiliogullari, L., (2013). “Operational Excellence”, System Publishing, ISBN: 978-605-446-355-8, 2017, İstanbul

Apiliogullari, L., (2017). "The New Dimension on Competition / Value Stream Management", Aura Publishing, ISBN: 978-605-103-343-3, İstanbul 
Black \& White Paper, (2017), "Enterprise Digital Transformation Strategies Turning Disruption into Differentiation", Century Link

Christopher, M, (2000), The Agile supply chain: Competing in volatile markets, International Marketing Management, Vol. 29, No. 1, pg. 37-44.

Darmois, E., at all, (2015), "IoT Standards Landscape - State of the Art Analysis and Evolution", River Publisher Series in Communications, ISBN: 978-87-93609-10-5

Dopico, M., at all, (2016), “A vision of industry 4.0 from an artificial intelligence point of view”, Int'l Conf. Artificial Intelligence | ICAI'16 |

Khan, A., Turowkski, K., (2016), “A Survey of Current Challengesis Preparation for Industry 4.0", Proceedings of the First International Scientific Conference Information Technologies for Industry" (IITI'16), Advances in Intelligentisepis Systems and Computing 450, DOI 10.1007/978-3-319-33609-1_2

Mila Malavasi, M., Schenetti, G., (2017). "Lean Manufacturing and Industry 4.0: an empirical analysis between Sustaining and Disruptive Change", Politecnico di Milano

Rohen, M., (2015), "IoT Driving Digital Transformation Impact on Economy and Society", River Publisher Series in Communications, ISBN: 978-87-93609-10-5

Simchi-Levi, D, Kaminski P, Simchi-Levi, E, (2009). Designing and managing the supply chain: Concepts, strategies and case studies, McGraw-Hill, New York

Silveria, G, Borenstein, D, (2001), Mass customization: Literature review and research directions, International journal of production economics, Vol. 72, 1-13.

Stratton, R, Warburton, R, (2003), The strategic integration of agile and lean supply, International Journal of Production Economics, Vol. 85, 183-198.

Towill, D, Christopher, M, (2002), The Supply chain strategy conundrum, International Journal of Logistics, Research and Applications, Vol. 5, No. 3.

Vermesan, O., at all, (2015) "Internet of Things Cognitive Transformation Technology Research Trendsisépiand Applications", River Publisher Series in Communications, ISBN: 978-87-93609-10-5

Yusuf, Y, Gunasekeran, A., (1999), Agile manufacturing: The drivers, concept and attributes, International Journal of Production Economics, Vol. 62, 33-43.

Yusuf, Y, Gunasekeran, A, (2004), Agile supply chain capabilities: Determinants of competitive objectives, International Journal of Production Economics, Vol. 159, 379-392. 